mento. Note-se também que a Enciclopédia Verbo (Vol. 9, 1969), normalmente com bons artigos sobre química, dada a categoria científica dos colaboradores desta área, só tem uma entrada em "Gasogénio", remetendo para "Gás de água" e aí um pequeno artigo onde cita só a reacção (2). Também a KirkOthmer Encyclopedia of Chemical Technology, Third Edition, John Wiley, New York, Vol. 11, p. 410, pouco diz de interesse para a discussão em causa.

\section{Cartas ao Editor}

Cartas ao editor discutindo material publicado em números recentes do Química, ou de interesse genérico em química nas suas várias vertentes, podem ser submetidas por correio electrónico ou convencional (ao editor, Departamento de Engenharia
Química - FEUP, Rua Dr. Roberto Frias, 4200-465 Porto). A recepção das cartas não é acusada, nem os autores consultados para a sua publicação, podendo ser editadas para publicação em parte, ou no todo, de acordo com as disponibilidades de espaço.

\title{
Noticiário SPQ
}

\section{Olimpíadas de Química Júnior 2005}

Na manhã do dia 9 de Abril de 2005, Sábado, os campus universitários do país animaram-se com a chegada de centenas de jovens, alunos dos $8 .^{\circ}$ e $9 .^{\circ}$ anos de escolaridade, que chegavam com os seus professores para participar nas "Olimpíadas de Química Júnior". Durante todo o dia, dezenas de docentes - e alunos - dos Departamentos de Química acolheram estes jovens competidores numa grande organização concertada de divulgação da Química e dos Departamentos de Química das universidades portuguesas.

No total, 736 alunos, oriundos de 114 Escolas Básicas, estiveram em Laboratórios de Química a realizar pequenas tarefas de Química, em 11 instituições universitárias. Uma colaboração SPQ Departamentos de Química - Escolas / / Professores que funcionou e da qual todos nos podemos orgulhar.

O sucesso da iniciativa mede-se, para já, pela satisfação dos muitos que a organizaram e daqueles a quem ela se dirigia: os nossos futuros químicos. E essa satisfação está bem evidenciada nos relatos que se seguem, elaborados pelos responsáveis da organização em cada instituição: por exemplo, quando os organizadores descrevem a sensação da equipa no fim de tudo - "Valeu a pena!" - ou quando nos referem as pré-inscri- ções para as "Júnior 2006", efectuadas por alunos já ansiosos por voltar (e talvez temerosos de que a oportunidade Ihes fuja!).

Mas o conjunto de relatos que se segue é mais do que um exercício de auto-elogio. É uma forma de registar os acontecimentos, reunir ideias e partilhar experiências. E contribuir para criar um modelo, o modelo "Olimpíadas de Química Júnior", que, tanto quanto sei, é único no país, quer a nível de organização, quer a nível das actividades "em laboratório" características de uma ciência experimental.
Em cada um destes relatos, os autores tentam salientar o que correu melhor, o que foi mais apreciado pelos alunos, o que resultou bem. As experiências assim partilhadas permitirão que a próxima edição seja ainda melhor em todos os locais. Boas ideias que podem ser adoptadas? Muitas! Os bonés coloridos da UA e as T-shirts coloridas da UTAD para distinguir as equipas, resultaram muito bem; a colaboração com centros de ciência e museus locais, que na UA permitiu acolher um número muito elevado de alunos, e foi também aproveitada na UAlg e na UBI para actividades

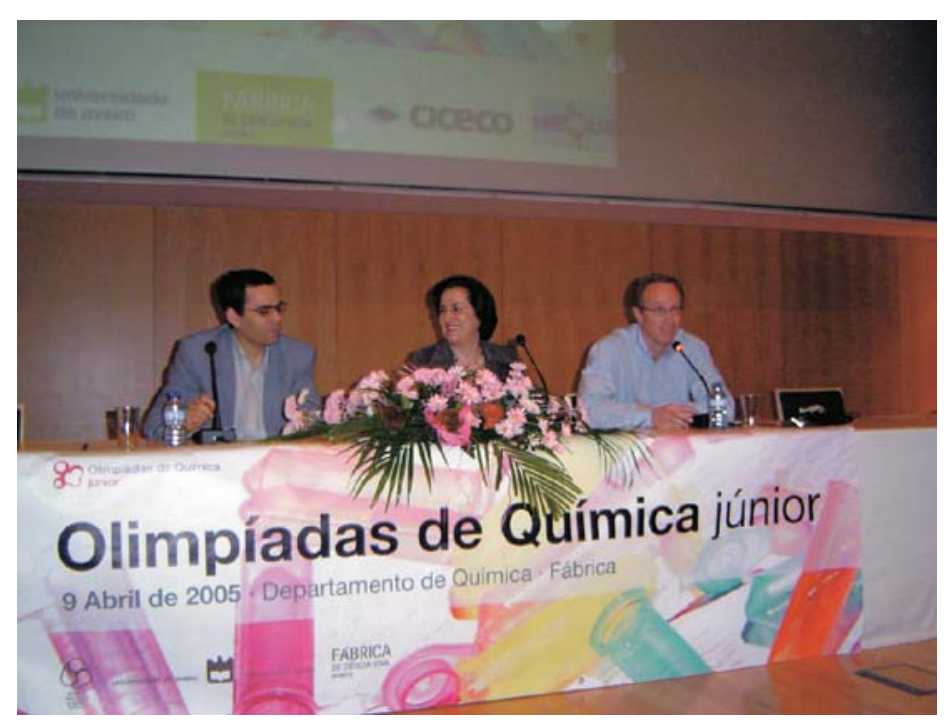

Abertura das Olimpíadas de Química Júnior na UA. A presença do presidente do Departamento de Química e de representantes da Reitoria foi uma regra em todas instituições, atestando a importância dada ao evento. 
complementares; o envolvimento dos núcleos de estudantes na UC e na UA; as parceria conseguidas na UP com as Editoras, na UC com uma entidade bancária, na UE com empresas; ...

E há também que não esquecer o que não correu tão bem, pois só assim se poderá corrigir nas próximas edições. Ficam aqui registados dois exemplos de coisas a corrigir. O primeiro é o mais complexo e tem a ver com a participação das escolas. O número de participantes efectivos foi elevado (736), mas ficou bem abaixo dos 920 alunos inicialmente inscritos. Alguns destes alunos não puderam participar, porque houve necessidade de limitar o número de equipas por escola. Mas houve também problemas de coordenação e comunicação entre instituições organizadoras que levaram algumas escolas a desistir de participar. E houve professores que cancelaram a sua participação quando se aperceberam que as provas iam decorrer ao Sábado... e houve escolas que simplesmente não compareceram, sem qualquer explicação. São situações que merecem reflexão, por parte da SPQ e dos organizadores locais, mas também por parte das escolas e dos professores. Se aos primeiros compete garantir uma organização eficiente, aos segundos pede-se que respeitem o trabalho desenvolvido e não defraudem as expectativas dos seus alunos.

O segundo exemplo (de coisas a corrigir) tem justamente a ver com as mais de duas centenas de professores que acompanharam os seus alunos nas "Olimpíadas de Química Júnior". Sendo absolutamente fundamentais à realização das "Júnior" - imaginem como seria realizá-las sem eles e percebem o que quero dizer - a verdade é que acabam por receber muito pouca atenção. Se isso até nem surpreende, pois toda a atenção está focada nos seus alunos, também é verdade que pode originar uma sensação de marginalização. O problema não é fácil de resolver, pois não é possível envolver os professores nas actividades competitivas. No entanto, deve ser possível encontrar uma solução que permita tornar-Ihes a visita às universidades mais agradável. Mais um desafio para a Edição de 2006!

o Coordenador das Olimpíadas de Química da SPQ Paulo Ribeiro Claro

\section{Universidade do Algarve}

LOCAL DA PROVA: Departamento de Química e Bioquímica da Faculdade de Ciências e Tecnologia, Campus de Gambelas.

Na primeira edição das Olímpiadas da Química Júnior (OQJ), realizadas a nível nacional, participaram seis Escolas Básicas da região do Algarve e Baixo Alentejo. Tendo sido inscritas pelas respectivas escolas, um total de 26 equipas das quais no dia 9 de Abril se apresentaram para as provas 24. Inicialmente o número de inscrições de escolas e alunos era superior, mais 11 equipas, que posteriormente acabaram por desistir da sua participação, devido ao facto das OQJ se realizarem a um sábado.

No dia da prova, o programa que se apresenta de seguida, foi apenas possível de realizar com a ajuda empenhada de docentes, funcionários e alunos das licenciaturas em Química e Física e Química do nosso Departamento.

\section{9:00-10:00 h}

Recepção informal

Átrio da Faculdade de Ciências e Tecnologia (Edifício C2)

9:45 h

Abertura oficial das Olimpíadas 2005

10:00-12:30 h

Provas

Laboratórios do Departamento de Química e Bioquímica e sala de computadores.

Jogos e Pintura

Ciência Viva - Campus de Gambelas

Nota: As equipas dividiram-se em dois grupos de equipas, estando metade no Ciência Viva e as restantes nas provas.

13:00-14:00 h

Almoço

Cantina da Universidade do Algarve no Campus da Penha
14:30 h

Divulgação de resultados e distribuição dos prémios

Anfiteatro Azul (Edifício C1)

No final todas as equipas obiveram pontuações superiores a 50\%, ficando as equipas classificadas em $2 .^{\circ}$ e $3 .^{\circ}$ Iugar com o mesmo resultado final, tendo sido necessário proceder ao desempate pelo tempo gasto na realização das provas respectivas.

Classificação Final

MEDALHA DE OURo: Marisa Silva, Rúben Costa, João Pedro Martins (EB23 de Júdice Fialho - Portimão)

MEDALHA DE PRATA: Miguel Ângelo R. Inácio, Jonas Dário Schulz, José Carlos G. Rocha (EB23 Damião de Odemira);

MEDAlHA DE BRONZE: Marta Alexandra J. Ramos, Luísa Miguel Guerreiro, Alexandra Cristina Silva (EB23 Damião de Odemira);

As escolas enviaram alguns comentários que gostariamos também de incluir, neste breve resumo do que foram as OQJ na nossa Universidade:

\section{Escola Básica dos $2 .^{\circ}$ e $3 .^{\circ}$ Ciclos de Júdice Fialho, Portimão.}

"No rescaldo das Olimpíadas da Química Júnior, é importante fazer uma retrospectiva e deixar registada a nossa opinião sobre a forma como as mesmas decorreram. Consideramos que a iniciativa é de louvar e de grande interesse e que irá fomentar o interesse dos alunos pela Química. Como tal, pensamos que se deverá repetir. Não podemos deixar de agradecer a forma como fomos tratados ao longo de todo o processo, obtendo sempre resposta, com prontidão, às nossas dúvidas e sendo recebidos de forma calorosa no dia da prova. Contudo, gostaríamos de lançar algumas sugestões, que pensamos, poderão tornar a participação nas provas ainda mais interessante:

- Deveria haver uma final a nível nacional, com as equipas que ficaram em primeiro lugar a nível regional; 
- Uma vez que a grande maioria dos alunos já visitaram centros de Ciência Viva (Faro, Lisboa, etc.) em visitas de estudo organizadas pelos grupos de Ciências Físico-Químicas das suas escolas, as actividades para os alunos que já fizeram as provas ou se encontram à espera das fazer poderiam ser mais enriquecedoras se fossem, por exemplo, experiências nos próprios laboratórios da Universidade, com alunos universitários;

- O regulamento deveria especificar que as equipas devem ser mistas (alunos de $8 .^{\circ}$ e $9 .^{\circ}$ ano);

- Deviam existir actividades para os professores acompanhantes, que ficam sem nada para fazer enquanto os seus alunos estão nas provas."

(Professoras Ana Carolina Sousa e Ana Cristina Mariano)

\section{Escola José Neves Júnior, Faro.}

"Em primeiro lugar quero felicitar toda a organização que esteve por detrás deste evento, foi muito bem organizado e delineado. Iniciativas destas são de louvar, pois habitualmente só as há nos grandes centros, ficando as cidades periféricas à margem, logo, bastante desfavorecidas. Os alunos gostaram imenso das provas teóricas e de laboratório e querem voltar a participar para o ano: já se pré-pré-inscreveram!

Queria apenas fazer uma pequena sugestão: o dia da semana em que foi realizada esta iniciativa (Sábado) talvez não tenha sido o mais correcto, porque nestas idades os alunos têm sempre imensas actividades extra-curriculares a serem desenvolvidas ao Sábado. Eu sei, tinha que ser num dia em que não houvesse aulas por uma questão de utilização de instalações e recursos humanos, mas não seria possível realizar as Olimpíadas em Maio, durante a Semana Académica? Foi só uma sugestão.

Volto a felicitar-vos e até à próxima!" (Professora Fernanda Duarte)

\section{Universidade de Aveiro}

Em 2004, o Departamento de Química da Universidade de Aveiro realizou uma edição experimental das "Olimpíadas de Química Júnior", a nível regional, com muita vontade mas poucas certezas. Os docentes do $D Q$ puseram à prova a sua imaginação para construir as tais "questões em laboratório", os professores das escolas concorrentes vieram a Aveiro ajudar a construir o programa de actividades, e os alunos foram participantes exemplares. E foi esta experiência bem sucedida que serviu de base à edição nacional de 2005

Para a edição de 2005, partimos com uma ambição bem definida: conseguir aumentar significativamente o número de alunos participantes e, simultaneamente, melhorar a qualidade do programa. Para isso nos empurrava não só a experiência já adquirida e a nossa vontade de fazer sempre mais e melhor, mas também a própria Reitoria da Universidade de Aveiro, que viu nas "Olimpíadas de Química Júnior" uma iniciativa a apoiar e lançou ao Departamento o desafio de ampliar a capacidade de acoIhimento, de modo a que nenhuma inscrição tivesse de ser recusada. Um objectivo demasiado ambicioso, mas que se mantém no horizonte...

O primeiro passo foi dado através de um protocolo de colaboração com a "Fábrica de Ciência Viva", um centro Ciência Viva da Universidade de Aveiro, instalado nos edifícios de uma antiga fábrica aveirense. A ideia de colaborar na organização das "Olimpíadas de Química Júnior" em parceria com o Departamento de Química foi acolhida de forma entusiástica pelo Director da "Fábrica", Prof. Paulo Trincão. Entre outras tarefas, a "Fábrica" ficou responsável pela imagem e divulgação do evento e pela organização de duas sessões para os alunos: "a cozinha é um laboratório", uma actividade de mãos na massa de 30 minutos com avaliação final, e "5000 metros debaixo do mar", um filme 3D de pura diversão (isto é, sem avaliação).
No Departamento de Química foram organizadas também duas sessões de actividades: a prova de "questões em laboratório", com cerca de 20 questões "práticas" (o núcleo comum a todas as universidades) e a sessão de "Química em acção": demonstrações em anfiteatro, seguidas de mais algumas perguntas para avaliação...

Para tomar conta dos alunos durante as pausas - os tempos de espera não ocupados foram um problema detectado em 2004 - foram contactados os alunos do NEQUA (Núcleo de Estudantes de Química da UA) que responderam afirmativamente e se mobilizaram para organizar diversas actividades ao ar livre, de acordo com as pausas de cada equipa.

No dia 9 de Abril, as 64 equipas participantes (num total de 192 alunos, representantes de 24 escolas) começaram a chegar ao campus da UA antes das 9h00. À entrada para o auditório da Reitoria, os alunos receberam um saco com brindes da UA, o folheto da SPQ "Química - um elemento vital no teu futuro" e um boné de cor.

A ideia dos bonés coloridos, da responsabilidade da equipa da "Fábrica", foi um dos detalhes apreciados pelos participantes. O programa de actividades previa a divisão das 60 equipas participantes em 6 grupos de 10 e essa divisão foi feita pela cor do boné. Assim, em vez dos grupos $1,2,3 \ldots$ ou $A, B, C, \ldots$ tivemos os grupos Branco, Amarelo, Laranja, Vermelho, Verde e Azul, facilmente identificáveis à distância!

Depois da sessão de abertura, onde estiveram presentes o presidente do $D Q$, Prof. Artur Silva, e a Sra. Vice-reitora da UA, Prof. Isabel Martins, os grupos seguiram os seus guias (pela cor do boné) para as primeiras actividades, com início previsto às 10 h30. Até às 15 h00 os grupos foram rodando pelos locais das sessões, de acordo com o plano traçado. A fim de evitar o congestionamento da cantina, os grupos tiveram diferentes horas de almoço, uns logo a partir das $12 \mathrm{~h} 00$, outros só depois das $13 \mathrm{~h} 30$. 
Para estes últimos, a "Fábrica" preparou um mata-bicho a meio da manhã.

Foi difícil saber qual a actividade preferida pelos alunos. Uns gostaram de saber que a cozinha é um laboratório, outros gostaram das demonstrações do cientista bem disposto, outros ainda gostaram mesmo foi de passar pelos laboratórios e "mexer naqueles aparelhos com que trabalham os cientistas"... Em todas as pausas, os concorrentes puderam apreciar as actividades preparadas pelo NEQUA. Pelo meio, vários participantes foram entrevistados pelos repórteres do programa 3810-UA (canal 2:), que fizeram uma reportagem bastante completa. Um dia cheio!

Às 16 h00 demos início à cerimónia de entrega de prémios. Como as respostas das equipas foram sendo corrigidas ao longo do dia, foi fácil cumprir o horário previsto. No final, a boa disposição prevaleceu (mesmo entre os classificados em 4. ${ }^{\circ}$ lugar!). Depois dos aplausos aos vencedores e a todos os participantes, o lanche de Encerramento fechou o dia em convívio. $E$, pelo tom das últimas conversas, os participantes levaram para casa a vontade de voltarem.

Equipas vencedoras da Edição de 2005 na Universidade de Aveiro:

MEDALHA DE OURO: Mafalda Santos, Beatriz Ferreira, Mariana Santos (ES José Estevão - Aveiro)

MEDALHA DE PRATA: Daniela Rodrigues, Cristiano Azevedo, Timo Ten Brinke (Escola Evaristo Nogueira - S. Romão)

medalHa de bronze: Susana Pina, Manuel Cruz, Tania Santos

(Colégio de Albergaria)

Brian Goodfellow Helena Carapuça

José Alberto Costa

Paulo Ribeiro Claro

(Coordenadores Locais na UA)

\section{Universidade da Beira Interior}

As Olimpíadas de Química Júnior na Universidade da Beira Interior contaram com presença de 47 alunos provenien- tes de 4 Escolas dos distritos de Castelo Branco e Guarda, nomeadamente: Escola Quinta das Palmeiras - Covilhã, Escola do Santa Clara - Guarda, Escola Básica $2 .^{\circ}$ e $3 .{ }^{\circ}$ Ciclos, Serra da Gardunha - Fundão e Escola Secundária/3 Gonçalo Anes Bandarra - Trancoso, e 9 professores acompanhantes. Estiveram também presentes alunos finalistas das Licenciaturas do Ensino da Física e Química, de Química Industrial e de Bioquímica que guiaram as equipas concorrentes no decorrer das provas.

O programa das Olimpíadas iniciou-se às $10 \mathrm{~h}$ com a sessão de abertura no Anfiteatro Professor Pinto Peixoto onde tomaram a palavra o Presidente do Departamento de Química, Doutor António Mendonça, e a Doutora Lurdes Ciríaco. Às 10.30h teve início o concurso tipo TV com a duração de 30 min com a prestação de todas as equipas. Às 11.15 min iniciou-se a prova de observação em bancada sendo realizada pelas várias equipas desfasadamente. Às $13 \mathrm{~h}$ foi servido o almoço pelos serviços sociais da UBI, na Cantina de Santo António, para todos os participantes. Às 14.30h realizou-se uma visita ao Museu dos Lanifícios da UBI. Neste espaço de tempo foram corrigidas as provas e apresentada a classificação de cada equipa e fez-se a entrega dos diplomas de participação aos alunos e certificados de presença aos professores, assim como de lembranças oferecidas pelo Gabinete de Relações Públicas da UBI Às $16 \mathrm{~h}$ procedeu-se à entrega das medalhas enviadas pela SPQ e de prémios oferecidos pela UBI às equipas vencedoras. $01 .^{\circ}$ e $3 .^{\circ}$ prémios foram ganhos pela Escola Quinta das Palmeiras - Covilhã sendo os membros das equipas, 1. prémio: Ana Carolina Cardoso A. dos Santos; Tiago André Pereira Marques e Lisa Raquel dos Santos Pinheiro; e 3. ${ }^{\circ}$ prémio: Ana Raquel Duarte Mouro; Joana Isabel Vaz e Ana Raquel Mendes da Paula Nunes. 0 2. ${ }^{\circ}$ prémio foi ganho por uma das equipas da Escola de Santa Clara - Guarda constituída pelos alunos: Ana Carolina Gonçalves de A. Xavier; Joana Romano de Carvalho e Lara Sofia Gonçalves Monteiro. Encer- rou-se as olimpíadas com o lanche convívio no bar da UBI às $16.30 \mathrm{~h}$.

Lurdes Ciríaco

(Coordenador Local na UBI)

\section{Universidade de Coimbra}

Decorreram, no passado dia 9 de Abril, tal como na restante maioria dos diferentes Departamentos de Química do país, as primeiras Olimpíadas de Química Júnior (OQJr). Como geralmente acontece com as novidades, existia entre todos os organizadores e participantes uma enorme expectativa sobre como iria decorrer o dia.

E foi assim que, ao átrio do Departamento de Química, começaram a chegar os "atletas" e os seus "treinadores". Uns madrugaram; pelas 8:15 já se via, nas imediações, animação e movimentação de alunos que vinham disputar a prova. A pouco e pouco todos foram chegando e o convívio inicial da recepção, marcado pelo reencontro com algumas caras conhecidas de antigos alunos, agora professores, foi ajudando à gradual descontracção entre participantes. Após a sessão de boas-vindas iniciou-se a prova com os concorrentes duas escolas desistiram na véspera (!!) fazendo baixar o número de 60 para 48 alunos - a darem o seu melhor. A prova dividiu-se em quatro partes (todas de igual peso na classificação final): três partes práticas (com 17 diferentes actividades) que decorreram em três laboratórios distintos e uma quarta escrita com temporização e perguntas, com respostas de escolha múltipla, projectadas em "Data Show". Foi realmente muito estimulante observar o entusiasmo com que os alunos efectuaram a prova. Alguns comentários que registámos, ajudam a ilustrar o ambiente vivido nas provas:

"pouco temos feito em laboratório e é uma pena pois é muito giro!"

Um aluno acidentado efectuou a prova de canadianas; durante as provas foi por diversas vezes questionado sobre se quereria sentar-se e descansar um pouco, ao que sempre, cheio de deter- 
minação e entusiasmo, respondeu: "não é preciso, eu estou bem!".

Mas de particular relevo foi o facto de, talvez por ser novidade, nenhuma escola da cidade de Coimbra ter aderido à iniciativa. No entanto, munidos de um extremo entusiasmo e quiçá maior motivação que os seus próprios professores, três alunos de escolas de Coimbra e arredores, reuniram-se numa equipa que designámos de "Escolas Unidas de Coimbra", vieram concorrer e ... ficaram em 2. ${ }^{\circ}$ lugar! Uns verdadeiros heróis!

Mas o dia não acabou com a prova. Após um merecido almoço, foi tempo de mais actividades... mas não para classificação! Assim tivemos a Dra. Maria João Melo, coadjuvada pelas Dras. Ana e Micaela, do Departamento de Conservação e Restauro da UNL, a proferir uma muito breve palestra ao que se seguiu uma actividade "hands-on" onde todos, alunos e professores, puderam contactar com os métodos, cores, corantes, etc., com que os nossos antepassados pintavam e, efectuarem eles próprios as suas pinturas com esses materiais. Diferentes vermelhos, azuis e amarelos foram cores que não faltaram! Quando finalmente se cansaram de pintar - 0 que de facto não aconteceu - foi tempo da visita ao Exploratório de Coimbra.

E finalmente os grandes vencedores do dia, que foram todos! Não só pelo que atrás ficou dito, mas porque todos obtiveram classificações superiores a $60 \%$. Mas glória aos vencedores:

MEDAlHa de ouro: Daniel Siopa, Diogo Paulino, Monique Gomes (EB23 de São Martinho do Porto)

MEDALHA DE PRATA: Henrique Baptista, Hugo Neves, João Carvalho, das "Escolas Unidas de Coimbra"

MEDALHA DE BRonZE: Maria João Soares, Sofia Ermida,Vânia Silva (EB23 Nery Capucho - Marinha Grande)

Todos eles galardoados numa cerimónia cheia de entusiasmo e vivacidade, cuja entrega de medalhas foi efectuada pelos Prof. Doutores Hugh Burrows, Sebastião
Formosinho e Fernando Pina. Este último, secretário-geral da SPQ, honrou-nos com a sua presença durante grande parte do dia. Aos vencedores e aos seus professores os nossos sinceros parabéns! Ser vencedor das 1.as OQJr terá sempre um lugar muito especial na história destes "Jogos" que se quer vivam por muitos e bons anos!

$\mathrm{Na}$ hora do adeus este foi substituído por um "até para o ano". Enfim, podemos dizer que entre todos (organização e participantes) ficou a sensação de que "valeu mesmo a pena fazer as OQJr!".

Por último, mas não menos importante, gostaria de prestar um especial agradecimento às entidades patrocinadoras. À Reitoria da Universidade de Coimbra, na pessoa do Magnífico Reitor Prof. Doutor Seabra Santos, sem me esquecer do Dr. Rafael Agostinho (do Gabinete de Comunicação e Identidade da UC) com quem fui acertando agulhas ao longo dos últimos dois meses; à direcção da FCTUC, na pessoa do Prof. Doutor Lélio Quaresma Lobo, que através do protocolo com o BPI tornou possível efectuar as Olimpíadas com muito meIhores condições e impacto; ao banco BPI (aqui na pessoa da Dra. Idalina Basílio sempre sensível a mais um ou outro pedido) pelo generoso patrocínio; ao Departamento de Química da FCTUC, nas pessoas do Prof. Doutor Sebastião Formosinho (que passou o dia inteiro a conviver com todos) e da Dra. Teresa Pinho e Melo, por todo o suporte (logístico e financeiro) à organização do evento; à SPQ que em boa altura resolveu lançar este desafio e cujo impacto será certamente real e visível em pouco tempo. Pode parecer estranho o agradecimento a estas duas últimas instituições, às quais pertenço; no entanto, foram a SPQ e o Departamento de Química da FCTUC, as reais entidades geradoras destas Olimpíadas. E como por detrás do que se vê, há sempre muitos mais a tornar possível as coisas, aqui ficam os nomes de todos aqueles que tiveram participação directa nestas OQJr em Coimbra (sem qualquer ordem alfa- bética ou hierárquica porque todos, à sua maneira, foram importantes):

Maria João Moreno, Jorge Costa Pereira, Catarina Ralha, Artur Valente, Sérgio Rodrigues, Ana Lúcia Cardoso, Telma Costa, Ana Lapinha, João Pina, Susana Takato, Raquel Rondão, Carla Gonçalves, e aos elementos do NEQ: Gabriel, Bruno, Salomé, Ricardo e Tânia.

A todos o meu muito obrigado! A Festa foi de todos!

João Sérgio Seixas de Melo (Coordenador Local na UC)

\section{Universidade de Évora}

Decorreram no passado dia 9 de Abril as Olimpíadas da Química Júnior, desta vez a nível regional. Na Universidade de Évora a organização esteve a cargo de uma equipa de docentes do Departamento de Química: António Manuel Neto Vaz (coordenador), António Candeias, António do Canto, Henrique Vicente, Isabel Cansado, José Maria dos Santos Arteiro, Margarida Figueiredo, Maria do Rosário Freixo e Maria Elmina Lopes.

Participaram seis das nove equipas inicialmente inscritas, vindas de três escolas da Região: Escola EB 2,3/S S. Sebastião de Mértola - 2 equipas (6 alunos); Escola EB 2,3 Dr. António Francisco Colaço de Castro Verde -3 equipas (9 alunos) e Escola Secundária Mouzinho da Silveira de Portalegre - 1 equipa (3 alunos). No Programa estiveram incluídas, para além das provas propriamente ditas que decorreram da parte da manhã, após a recepção das equipas e a sessão de abertura, uma visita guiada ao Centro histórico da Cidade e uma visita aos laboratórios de Química.

A Universidade de Évora apoiou a organização através da oferta do almoço, do lanche e de pequenas lembranças para todos os participantes. Tivemos ainda a colaboração da Câmara Municipal de Évora através da oferta da visita guiada e de livros sobre a cidade. As empresas Delta Cafés e José Manuel Gomes dos Santos colaboraram através da oferta de pequenas lembranças tais como cami- 
solas, bonés, canetas, sacos e tabelas periódicas que todos receberam com agrado.

A sessão de divulgação dos resultados e entrega de prémios decorreu de forma muito animada tendo ficado classificadas nos três primeiros lugares as seguintes equipas:

MEDALHA DE OURO: Diana Correia, João Barradas e Ana Candeias (ES Mouzinho da Silveira - Portalegre)

MEDALHA DE PRATA: Ana Mestre, António Sampaio e Vítor Costa (EB23/S S. Sebastião - Mértola)

MEDALHA DE BRONZE: Isabel Celestino, Luís Martins e Catarina Guita (EB23/S S. Sebastião - Mértola)

De realçar o facto da equipa classificada em 3. Iugar ser constituída por alunos do $8 .^{\circ}$ ano de escolaridade.

Margarida Figueiredo (Coordenador Local na UE)

\section{Universidade de Lisboa}

Terminadas as provas das Olimpíadas de Química Júnior decorridas no Departamento de Química e Bioquímica da Faculdade de Ciências da Universidade de Lisboa, em cada uma das pessoas que mais estiveram envolvidas sobressaiu, de imediato, um único sentimento "Valeu a pena!".

No evento participaram alunos e professores de 5 Escolas: Escola Básica 2,3 de Ribamar (Lourinhã), o Instituto de Odivelas e a Escola Octávio Duarte Ferreira (Tramagal), todas com uma equipa, a Escola Secundária Miguel Torga (Massamá), com duas equipas, e a Escola Secundária de Coruche, com seis equipas. A Escola Dr. João das Regras (Lourinhã), com 1 equipa e a Escola E,B 2,3 de Alverca, com 5 equipas, cancelaram a sua participação, esta última apenas 2 dias antes.

Os participantes começaram a chegar ao campus da FCUL bem cedo, e, de acordo com o programa, a partir das 9 horas da manhã foram recebidos com um pequeno almoço, gentilmente ofere- cido pela Comissão Executiva do DQB, que também ofereceu o almoço e o lanche.

Pelas 10 horas teve lugar, num dos anfiteatros do edifício C8, a Abertura Oficial das Olimpíadas Júnior, uma cerimónia presidida pelo Presidente do Conselho Científico e Directivo da FCUL, por um representante da Presidente do DQB e pelos Coordenadores das Olímpiadas de Química Júnior no DQB-FCUL.

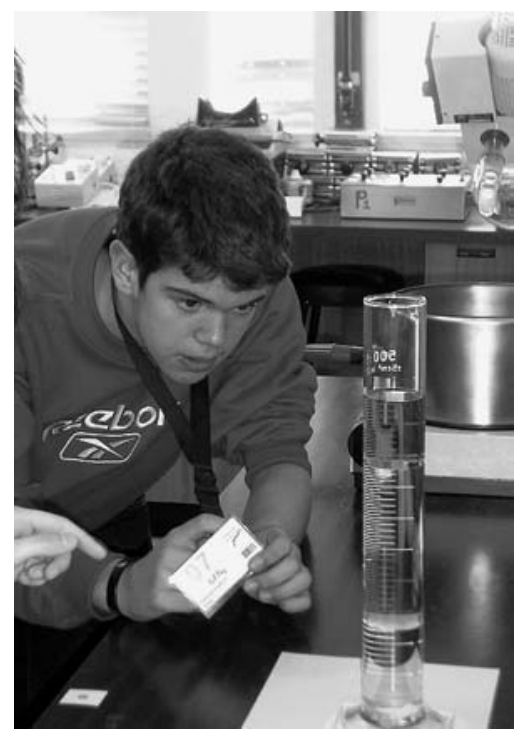

Alunos em prova na UM.

Foram enunciadas as regras: 30 perguntas, em cada uma delas apenas uma opção certa. Classificação de 1 ponto para resposta certa; 0 pontos para nenhuma resposta e desconto de 0,5 ponto para resposta errada. 0 tempo total de realização seria critério de desempate.

Seguiu-se um período de 2 horas e 30 minutos destinado à realização das Provas das Olimpíadas, em que os participantes foram chamados a responder a um conjunto de 30 questões, algumas de carácter teórico, respondidas numa sala de aula, e outras de carácter mais experimental (observações experimentais, medições, etc.) montadas e dupli- cadas em 2 laboratórios. Cada uma das 11 equipas tinha um delegado da FCUL, recrutado entre alunos e docentes, responsável por acompanhar a prestação dessa equipa, pela sua deslocação entre a sala e o laboratório, cronometrando o respectivo tempo de realização.

E ... chegámos ao período de almoço (bem merecido!)

Enquanto eram corrigidas as provas por um júri de 5 docentes do DQB, decorreu, num laboratório, um interessante conjunto de experiências, preparado por alguns docentes do DQB, que, visivelmente, animou uma grande parte do período da tarde.

Magia com a voz, Uma questão de espumas, Chove ou faz Sol? Uma simples cor permite adivinhar, Super balões, Um pirilampo no laboratório, Peganhento e divertido e Azul fugitivo foram as actividades experimentais que envolveram os participantes, alunos e professores, numa animada tarde laboratorial.

As Olimpíadas estavam quase a terminar, mas ninguém queria "arredar pé" do laboratório ... tal era o entusiasmo.

Eram 16 horas e 30 minutos quando teve lugar a Sessão de Encerramento das Olimpíadas. A todos os participantes foram distribuídos diplomas e prémios de participação, estes últimos oferecidos pelo Conselho Directivo da FCUL.

Foram anunciadas as 8 Escolas que tinham ficado em 4. ${ }^{\circ}$ lugar ex-aequo.

A representante da Presidente do DQB anunciou o terceiro lugar, que foi para a Equipa N. ${ }^{\circ} 02$ da Escola Secundária de Coruche, constituída pelas alunas Denise Inês Simões Janeiro, Sara Isabel Cordeiro Coelho e Sofia Raquel Castro Fernandes, e entregou-Ihes as medalhas de bronze e um prémio oferecido pelo Conselho Directivo da FCUL.

Um dos Vogais do Conselho Directivo da FCUL anunciou, seguidamente, o segundo lugar, que foi para a equipa $\mathrm{N} .{ }^{\circ}$ 07 da Escola Secundária Miguel Torga, constituída pelos alunos Hélder Miguel 
Fernandes Batista, Nuno Alexandre de Almeida Salgueiro e Sofia de Almeida Oliveira de Albergaria, e entregou-Ihes as medalhas de prata e um prémio oferecido pelo Conselho Directivo da FCUL.

Finalmente, o Presidente do Conselho Científico e Directivo da FCUL anunciou o primeiro lugar, que foi para a Equipa N. ${ }^{\circ} 05$ da Escola Secundária de Coruche, constituída pelos alunos André Miguel Ramos Travessa, Joana Isabel Almeida Mendes e João Coelho Pereira Prancha, e entregou-lhes as medalhas de ouro e um prémio, também este, oferecido pelo Conselho Directivo da FCUL.

Todos manifestaram ter gostado, ter participado na festa e quererem voltar!

A concluir que a semente ficou!

Maria Manuela Gomes da Silva Rocha Carlos Manuel Ferreira de Sousa Borges (Coordenadores Locais no DQB-FCUL)

\section{Universidade do Minho}

O departamento de Química da Universidade do Minho associou-se à iniciativa Olimpíadas de Química Júnior 2005 em colaboração com a SPQ. No dia do evento estiveram presentes no Campus de Gualtar, em Braga, 117 alunos provenientes de 12 escolas da região, acompanhados por 29 professores.

A sessão de abertura teve início às 10h30, no Anfiteatro da Escola de Ciências e estiveram presentes: o vice-Reitor Prof. Manuel Mota, em representação do Sr. Reitor, o presidente da Escola de Ciências Prof. João Ferreira e o Director do departamento de Química Prof. Michael Smith. A prova, com início às $11 \mathrm{~h}$, decorreu nos laboratórios de ensino do departamento de Química. Durante 90 min. as 39 equipas responderam em simultâneo e em rotatividade a 40 questões, baseadas em situações experimentais por observação, manipulação ou medição simples.

Finda a prova os alunos participantes puderam recarregar "baterias" na cantina da UM, onde Ihes foi oferecido um almoço que parece ter sido do agrado de todos. No final do almoço fez-se um passeio de reconhecimento ao Campus, sempre acompanhados por um sol radiante. De volta ao anfiteatro iniciaram-se as actividades da tarde com uma apresentação sobre as perspectivas de uma formação universitária em Química.

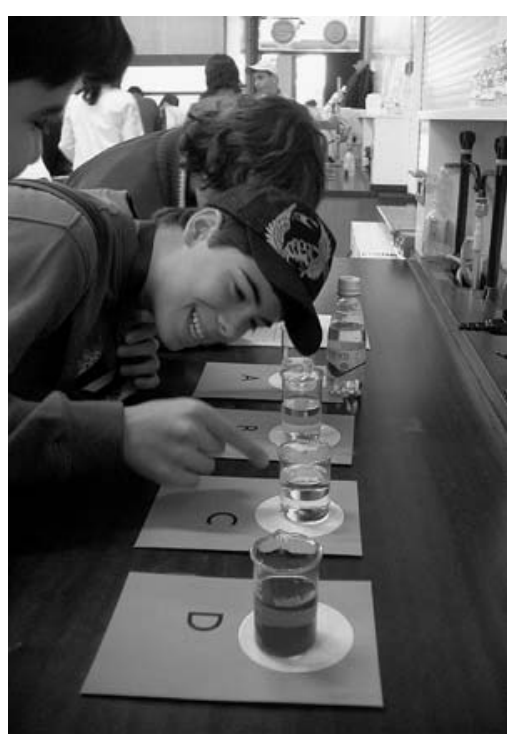

A boa disposição dos concorrentes foi uma constante durante todas as provas.

A ansiedade foi crescendo até às $15 \mathrm{~h} 30$, altura em que foram anunciados os nomes dos laureados. Assim, o bronze foi para a equipa da Escola EB2,3 do Cávado, Braga, constituída pelas alunas Fabiana Gomes, Filipa Roriz e Joana Lopes. A prata foi para os alunos Ana Oliveira, Marta Machado e José Pinto da Escola EB2,3 Egas Moniz, Guimarães, para onde também foi o ouro atribuído à equipa formada pelos alunos Ângela Machado, João Alves e Vítor Vaz da Escola EB2,3 de Pevidém. Para além das medalhas, estes alunos foram brindados pelo departamento de Química com outros prémios (com destaque para as miniaturas de material de vidro de laboratório e conjuntos magnéticos Geo- mag). Houve também lembranças para todos os participantes.

À saída foram distribuídos farnéis para a viagem de regresso.

A adesão e motivação demonstradas pelos alunos deixaram a sensação grata e estimulante de que iniciativas como esta devem ter continuidade. Assim, foi reconhecida por parte do departamento de Química da UM a importância da integração das OQJ no seu plano anual de actividades. Finalmente um louvor para os professores que acompanharam os alunos: foram eles que Ihes incutiram 0 gosto pela descoberta científica.

A cobertura do evento foi feita pelos principais órgãos de comunicação social da região. Algumas das fotos do acontecimento estão disponíveis em: www.uminho.pt/visitasescolas, no link fotos.

Dulce Geraldo

Fátima Bento

João Paulo André

(Coordenadores Locais na UMinho)

\section{Universidade Nova de Lisboa / ITQB}

Num evento que mobilizou 24 alunos concorrentes, cerca de 6 professores acompanhantes e 8 membros da equipa organizadora do Instituto de Tecnologia Química e Biológica (ITQB), a sensação final de quem participou, quer do "lado de cá", quer do "lado de lá", é que "valeu a pena!".

De uma forma geral os participantes, provenientes da Escola Secundária da Quinta do Marquês (Oeiras), da Escola Salesiana de Sto António (Estoril), do Colégio Salesiano Oficinas de S. José (Lisboa) e Escola EB 2,3 Dr. Joaquim de Barros (Oeiras) começaram a chegar aos campus do ITQB bem cedo, e, de acordo com o programa, a partir das 9 horas da manhã foram recebidos pela organização.

Pelas 10 horas teve lugar a cerimónia de Abertura Oficial das Olimpíadas Júnior, realizada num dos anfiteatros do ITQB. A cerimónia foi presidida pelo Director do ITQB, Prof. Peter Lindley, e pelo Coorde- 
nador local das Olímpiadas de Química Júnior no ITQB, Prof. António Lopes.

Depois das boas vindas, foi anunciado o programa das provas e foram enunciadas as regras a todos os presentes:

- 30 perguntas, em cada uma delas apenas uma opção certa.

- classificação de 1 ponto para resposta certa; 0 pontos para nenhuma resposta e desconto de 0,5 ponto para resposta errada.

- o tempo total de realização seria critério de desempate.

- os professores acompanhantes dos alunos não podiam contactar os alunos até o términus das provas.

Seguiu-se um período de 2 horas a 2 horas e 30 minutos destinado à realização das Provas das Olimpíadas. Os participantes foram chamados a responder ao conjunto de 30 questões, algumas de carácter teórico, respondidas numa sala de aula, e outras de carácter mais experimental (observações experimentais, medições, etc.) montadas em laboratórios.

Cada uma das equipas tinha um "delegado" da instituição de acolhimento, recrutado entre alunos e docentes, responsável por acompanhar a prestação dessa equipa, pela sua deslocação entre a sala e o laboratório, cronometrando o respectivo tempo de realização. Enquanto decorriam as provas para alguns dos participantes, os restantes assistiram (depois revezaram-se) à projecção de resumos do "Dia Aberto" do ITQB, que teve lugar recentemente. Do mesmo modo todos os participantes quiseram responder "entusiasticamente" ao inquérito "Tens queda para a Química?" elaborado pela SPQ.

E ... chegámos ao período de almoço (bem merecido!) gentilmente oferecido pela Câmara Municipal de Oeiras, que assim se quis associar ao evento.

Enquanto eram corrigidas as provas por um júri de docentes, decorreram "actividades paralelas" experimentais que envolveram os participantes, alunos e pro- fessores, numa animada tarde laboratorial, com um interessante conjunto de experiências, preparado por alguns docentes do ITQB, que, visivelmente, animou uma grande parte do período da tarde: Corantes dos M\&M's, Quem é mais denso?, Cores falsas e cores verdadeiras, Falsificação e Detectives, Rochas "mágicas", Vamos fazer pirilampos foram alguns dos "best-sellers". As Olimpíadas estavam quase a terminar, mas ninguém queria "arredar pé" do laboratório ... tal era o entusiasmo.

Cerca das 16 horas, teve lugar a Sessão de Encerramento das Olimpíadas, presidida pelos mesmos representantes da sessão de Abertura. A todos os participantes foram distribuídos diplomas e prémios de participação.

Seguidamente foram anunciadas as Escolas que tinham ficado em $4 .^{\circ}$ lugar ex-aequo, e depois foram anunciadas as equipas por ordem de posicionamento $\left(3 .^{\circ}, 2 .^{\circ}\right.$ e $\left.1 .^{\circ}\right)$. Cada uma destas equipas recebeu ainda um diploma da SPQ atestando a obtenção desse prémio e a respectiva medalha de "Bronze", "Prata" e "Ouro", respectivamente.

MEDALHA DE BRonze: Gonçalo Amorim, Pedro Barroca, Simão Arouca (Escola Salesiana de Sto António).

MEDALHA DE PRATA: Sara Brandão, João Rebelo, André Abreu (ES Quinta do Marquês).

MEDALHA DE OURo: Diogo Amorim, Manuel Toscano, José Pinto Basto (Escola Salesiana de Sto António).

Todos manifestaram ter gostado, ter participado na festa e quererem voltar! Tanto é assim que já ficaram algumas equipas "inscritas" para a próxima edição das provas.

Afinal "a Química mexe"... e a semente parece que ficou!

António Lopes (Coordenador Local no ITQB)

\section{Universidade do Porto}

Na Universidade do Porto, a primeira edição das Olimpíadas de Química Jú- nior teve lugar no Departamento de Química da Faculdade de Ciências, tendo despertado o interesse de 28 Escolas, que inscreveram 71 equipas compostas por 213 estudantes! Por razões logísticas e económicas, só pudemos aceitar a inscrição de 1 equipa por Escola, num total de 84 estudantes concorrentes. Apesar da nossa limitada capacidade de resposta, procuramos compensar os participantes com um sábado bem diferente do habitual, vivido em ambiente agradável, proporcionando-Ihes uma visão positiva (mas real) da Química, cuja imagem esperamos que venham a reter e a difundir.

Os docentes do Departamento de Química mobilizaram-se para responder a este desafio, desenvolvendo um grande esforço para preparar a prova: várias "experiências e questões do dia-a-dia", expostas em 5 Laboratórios e 1 Anfiteatro, visitados por grupos de concorrentes, acompanhados por guias (alunos finalistas de um dos cursos do Departamento - Curso de Química / Ramo Educacional) muito motivados para o convívio com aqueles jovens.

O esforço da manhã foi compensado pelo almoço realizado nas instalações do bar do Departamento, em que se reuniram, em agradável confraternização, os membros das equipas representantes de todas as Escolas, os professores responsáveis pelas equipas e os guias. Após o almoço, a animação continuou com uma sessão orientada pelo Doutor João Paiva que, de modo ímpar, cativou a atenção de todos os presentes, pela forma motivante e bem disposta como tratou vários aspectos químicos do quotidiano.

O dia, apesar de já tão preenchido, ainda não tinha terminado. A divulgação dos resultados e a entrega dos prémios foram realizados na sessão de encerramento, em que receberam prémios todos os membros das três equipas meIhor classificadas, todas as escolas participantes, bem como os professores acompanhantes. Os apoios da Porto Editora, da Texto Editora e do Exploratório Infante D. Henrique permitiram-nos 
este agradável mimo! Claro que o fim da festa aconteceu, mais uma vez, nas instalações do bar, com um lanche participado por todos.

A correcção e classificação das provas esteve a cargo do grupo dos 8 docentes responsáveis pela concretização da prova, tendo sido tornados públicos os nomes das Escolas com as três melhores classificações. Cumpre-nos realçar que todas as Escolas participantes tiveram bons resultados, com classificações no intervalo [56,2\% - 93,7\%]. Para o Departamento de Química - FCUP, tal resultado global é muito gratificante... Aos alunos concorrentes e aos seus professores, PARABÉNS!

Resta-nos agradecer à Reitoria da Universidade do Porto e à Direcção da Faculdade de Ciências o apoio dado a esta iniciativa.

http://www.fc.up.pt/qui/olimpiadas/junior/2005/DQ_Foi_Novidade_OlyQuimJunior2005.html

Vencedores

MEDALHA DE OURO: André Amorim, Carlos Moreira, Nuno Moreira (Externato das Escravas do Sagrado Coração de Jesus)

MEDAlHA DE PRATA: Ana Raquel Gomes Ferreira, Diana Martins, Joana Vasconcelos (EB23 Soares dos Reis)

MEDALHA DE BRONZE: Alexandre, José Paulo, João Barroso (ES/3 Aurélia de Sousa)

Maria das Dores M. C. Ribeiro da Silva (Coordenador Local na UP)

\section{Universidade Técnica de Lisboa}

A realização, pela primeira vez, das Olimpíadas de Química Júnior permitiu, mais do que a realização de uma competição, que foi de facto, um ambiente de convívio entre alunos, professores acompanhantes e professores organizadores em torno da Química. Por isso, este evento decorreu num ambiente descontraído.

O programa cumprido no Departamento de Engenharia Química do Instituto Su- perior Técnico (DEQ-IST) iniciou-se com recepção informal dos participantes no átrio da Torre Sul e com entrega de documentação aos professores acompanhantes. Seguiu-se uma curta sessão de boas vindas e de exposição do modo como iriam decorrer as provas e o programa para o dia. Compareceram 4 escolas: EB23 D. Miguel de Almeida (Abrantes), Escola Secundária Dr. António Carvalho Figueiredo (Loures); Colégio Campo de Flores (Lazarim) e EB23 Piscinas (Lisboa), que participaram com uma, duas, três e quatro equipas, respectivamente, num total de 28 alunos.

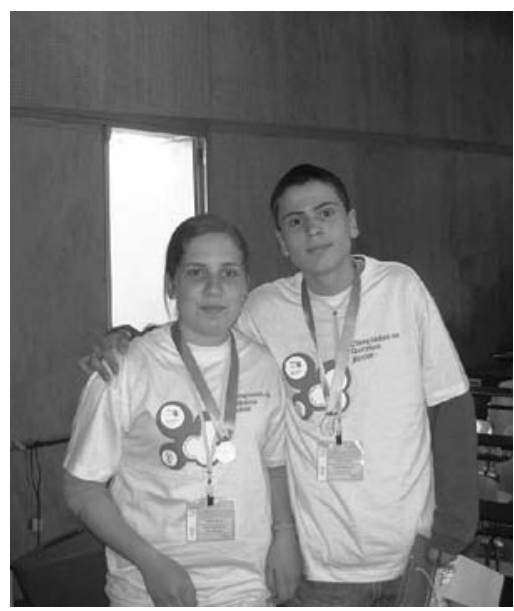

A equipa vencedora na UTAD. As equipas de dois alunos também podem ganhar, mas a surpresa foi a presença de várias equipas do 8. ${ }^{\circ}$ ano ente os vencedores.

Com as várias equipas foram constituídos três grupos, tendo as provas decorrido em três Laboratórios, que foram sequencialmente visitados. Após a prova, que, por ter havido desistências, decorreu mais rapidamente que o previsto, houve um pequeno compasso de espera, que permitiu aos participantes passearem-se pelo campus do IST, visto que o tempo estava convidativo.

No final do almoço, os participantes assistiram a uma sessão sobre "luz e côr" apresentada pelos Professores Mário
Nuno Berberan e Manuel Prieto. Esta apresentação foi uma versão mais curta de uma Palestra (Luz Sobre as Moléculas) que estes colegas têm vindo a apresentar em várias escolas do País.

Terminada esta sessão, seguiu-se a esperada divulgação dos resultados das provas e entrega de prémios. Como é habitual nas Olimpíadas de Química, anunciou-se que sete equipas tinham ficado, ex-aequo, em 4..$^{\circ}$ lugar. Em 3. ${ }^{\circ}$ lugar ficou a equipa constituída pelos alunos Lydia Neto, Ricardo Magalhães e Tiago Oliveira da EB23 Piscinas de Lisboa. Em 2. ${ }^{\circ}$ Iugar ficou a equipa constituída por Ana Cláudia, Manuel Araújo e João Félix do Colégio Campo de Flores. Finalmente, o $1 .^{\circ}$ Iugar foi conseguido pelos alunos Sara Parreira e Tiago Pereira, também do Colégio Campo de Flores. Após a entrega das correspondentes medalhas, procedeu-se ao encerramento desta edição Olimpíadas.

Das conversas com alunos e professores acompanhantes registam-se a satisfação da participação e sugestões para a próxima edição destas Olimpíadas.

Para os organizadores do evento no DEQ-IST ficaram a satisfação do prazer demonstrado pelos participantes e a confirmação da importância que este tipo de iniciativas da SPQ tem no despertar do interesse dos alunos para as Ciências, em particular para a Química.

Jorge Morgado (Coordenador Local na UTL)

\section{Universidade de Trás-os-Montes e Alto Douro}

A 1. ${ }^{a}$ edição Nacional das Olimpíadas de Química Júnior na Universidade de Trás-os-Montes e Alto Douro reuniu 70 alunos e 24 professores acompanhantes de 13 escolas de vários concelhos da região. As provas decorreram durante a tarde e foram organizadas em 2 laboratórios e uma sala contendo cada um cerca de 20 perguntas baseadas, essencialmente, na observação e manipulação de experiências laboratoriais. Após uma rápida apresentação da prova foram distribuídas aos alunos, agrupa- 
dos em equipas de 2-3 elementos, Tshirts coloridas (3 cores), com o símbolo da SPQ, UTAD e Olimpíadas Júnior o que nos permitiu dividi-los em 3 grandes grupos. Deste modo cada grupo começou a prova numa sala diferente procedendo-se de seguida à rotação dos grupos. Esta opção permitiu que todos os alunos realizassem uma prova contínua com poucos tempos mortos em cerca de 2 horas. Seguiu-se um lanche durante o qual a organização procedeu à rápida correcção das provas. A reali- zação das Olimpíadas de Química Júnior contou com o imprescindível apoio da Pró-Reitoria para as Relações Públicas e Imagem da UTAD, bem como da Câmara Municipal de Vila Real. Associaram-se também a este evento, na qualidade de patrocinadores, o hipermercado Continente, a Minfo Gráfica e as pastelarias Docinho e Bela Aurora da cidade de Vila Real.

Nos 3 primeiros lugares ficaram as seguintes equipas: medalha de ouro: Camile Martins e Ricardo Taveira (Escola EB23 de Amarante).

MEDALHA DE PRATA: Gabriela Pereira, Íris Santos e Pedro Teixeira (ES Fernão de Magalhães - Chaves).

MEDAlHA DE BRONZE: Inês Almeida, Ana Melo e Rui Castro (Colégio de Nossa Senhora da Boavista - Vila Real).

Paulo Coelho

(Coordenador Local na UTAD)

\section{Encontro de Química dos Alimentos}

\section{Alimentos: Tradição e Inovação, Saúde e Segurança}

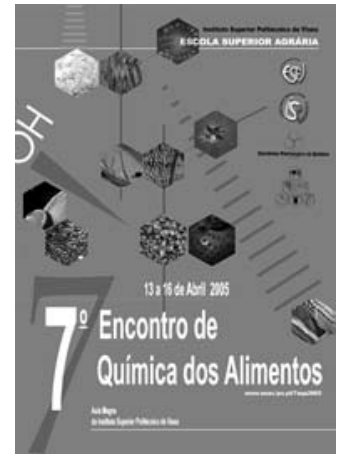

Realizou-se na Aula Magna do Instituto Politécnico de Viseu, entre os dias 13 e 15 de Abril de 2005, o 7. Encontro de Química dos Alimentos subordinado ao tema Tradição e Inovação, Saúde e Segurança, e que resultou de uma organização conjunta entre a Sociedade Portuguesa de Química e a Escola Superior Agrária de Viseu. Na página web www.esav.ipv.pt/7eqa2005 podem consultar-se todas as comunicações oral, e em painel, que integraram o programa científico. Estes Encontros que se têm vindo a realizar desde 1993 com frequência bienal, tiveram as suas edições anteriores em Santarém, Aveiro, Faro, Coimbra, Porto e Lisboa.
Os Encontros de Química dos Alimentos efectuam-se no âmbito das actividades promovidas pela Divisão de Química dos Alimentos da Sociedade Portuguesa de Química, e é, em Portugal, uma referência no domínio da química e da ciência dos alimentos.

O Encontro reuniu a comunidade científica, académica e o meio industrial, num total de cerca de 400 congressistas, verificando-se uma partilha de conhecimentos e uma viva discussão em torno desta área de investigação que é a química dos alimentos e de todas as ciências que com ela se relacionam. Contou-se ainda com a presença de oradores internacionais oriundos de empresas/ /centros de investigação, tais como a Unilever Health Institute (Holanda), LGC (Reino Unido) e Inter Rhône (França).

Durante as sessões foram abordadas diversas metodologias para a caracterização e análise de produtos alimentares, com particular relevância para os produtos tradicionais. Como exemplo dos grandes progressos que ocorreram recentemente nas análises bioquímicas, focou-se a utilização de marcadores de $A D N$, que constitui actualmente uma ferramenta indispensável à condução da produção pecuária, bem como ao estabelecimento de sistemas de rastreabilidade das carnes. As análises físico-químicas clássicas conjugadas com os novos tratamentos de resultados mediante análise estatística multivariável continuam a prestar bons serviços para a caracterização e distinção de produtos (por ex. mel de diferentes origens). Particular importância foi dada também às temáticas das interacções entre os vários constituintes alimentares, à aplicação de novas tecnologias de processamento e conservação na manutenção ou alteração das características físico-químicas e sensoriais dos alimentos. Todas estas temáticas têm como objectivo último a satisfação do consumidor. Tendo em consideração as exigências do consumidor em relação à saúde, e a importância cada vez maior que os alimentos funcionais representam na dieta alimentar, alguns estudos apresentados realçaram a alteração da composição nutricional dos alimentos através da incorporação ou remoção de alguns dos seus constituintes.

Os factores de risco e ainda os comportamentos alimentares foram também objecto de análise de uma mesa redonda intitulada Comportamentos Alimentares e Estilos de Vida, constituída pelos seguintes conferencistas convidados: Prof. Dra. Rosaura Leis Trabazo - Faculdade de Medicina, Universidade de Santiago de Compostela, Prof. Dra. Isabel do Carmo - Faculdade de Medicina, Universidade de Lisboa; Prof. Dra. Cristina Padez - Departamento de Antropologia, Universidade de Coimbra; Dra. Vanessa Candeias - Direcção Geral de Saúde / Instituto de Medicina Preventiva 
da Faculdade de Medicina da Universidade de Lisboa. Assim, discutiram-se as consequências na saúde humana dos erros alimentares associados aos actuais estilos de vida.

Os produtos agro-alimentares tradicionais foram também objecto de discussão de uma mesa redonda subordinada ao tema Inovar na Tradição. Face aos conhecimentos actuais de nutrição, os alimentos tradicionais devem continuar a integrar a nossa dieta alimentar, contudo uma componente de inovação é imprescindível de forma a obterem-se produtos de melhor qualidade e higiene, garantindo a genuinidade e salvaguardando a saúde do consumidor. A me-
Ihoria das técnicas de marketing é também um dos factores necessários no sentido de promover os produtos agroalimentares tradicionais. A inovação na tradição é um factor determinante do desenvolvimento rural e, como tal, deverá merecer no futuro próximo apoios específicos mais importantes.

A Comissão Científica do 7EQA

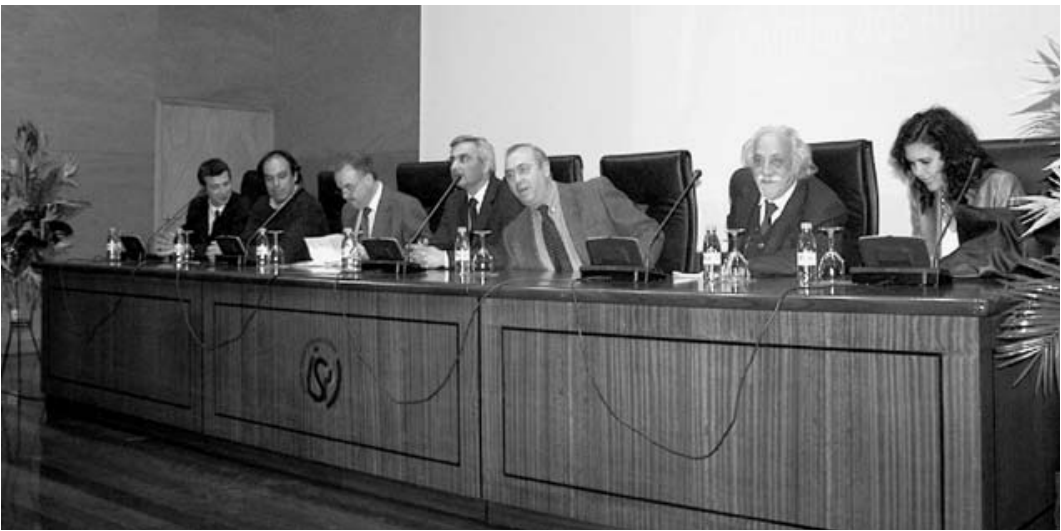

Momento da Cerimónia de Abertura. Da esquerda para a direita: Telmo Cardoso (Presidente da Associação de Estudantes da Escola Superior Agrária de Viseu), Eng. ${ }^{\circ}$ Pedro Rodrigues (Presidente do Conselho Directivo da ESAV), Dr. Américo Nunes (Vice-Presidente da Câmara Municipal de Viseu), Dr. Acácio Pinto (Governador Civil do Distrito de Viseu), Prof. Doutor João Pedro Antas de Barros (Presidente do Instituto Politécnico de Viseu), Prof. Doutor José da Costa Lima (Vice-Presidente da Sociedade Portuguesa de Química) e Prof. Doutora Dulcineia Ferreira (Presidente da Comissão Organizadora do $7 \mathrm{EQA}$ )

\section{Vice-Presidente da SPQ eleito membro da Academia Brasileira de Ciências}

O Vice-Presidente da Sociedade Portuguesa de Química, professor catedrático da Universidade do Porto José Luís Fontes da Costa Lima, foi eleito membro da Academia Brasileira de Ciências (ABC). É o terceiro português honrado com esta distinção depois de Ana Maria Ribeiro Neiva (Universidade de Coimbra) em 1997 e de António Coutinho (Instituto Gulbenkian de Ciência) em 2003.

A distinção, que foi oficializada no dia 8 de Junho, no Palácio Gustavo Capanema, RJ, Brasil, numa cerimónia presidida pelo Presidente brasileiro, Lula da Silva, teve por fundamento o currículo científico de José Luís Costa Lima, com cerca de 319 artigos publicados em revistas científicas internacionais, e a sua longa colaboração com investigadores brasileiros da qual resultaram 50 artigos em co-autoria.

Esta distinção surge na sequência de uma já longa e fecunda colaboração

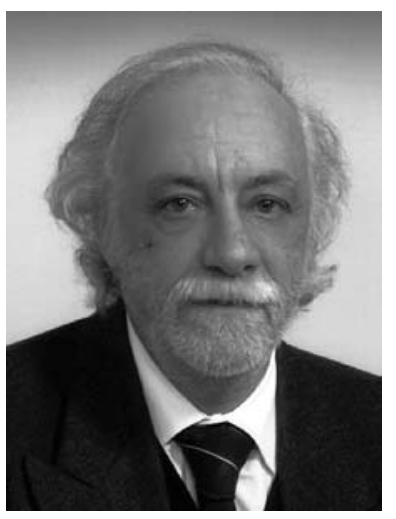

grupo realizaram missões de trabalho no Brasil. Esta interacção tem repercussões aos mais variados níveis da cooperação científica entre os dois países, sendo um exemplo a presença de autores brasileiros nas páginas deste boletim.

A $A B C$, um dos mais importantes organismos da comunidade científica brasileira, elege todos os anos novos membros de várias áreas científicas. Os novos membros, 19 académicos brasiIuso-brasileira iniciada em 1989, tendo desenvolvido e colaborado em projectos de investigação conjuntos na área da Química Analítica e sido chamado regularmente a fazer parte do corpo docente de diversos programas de educação avançada no Brasil. Esta interacção científica inclui diversas instituições brasileiras, como a USP, UNICAMP, EMBRAPA, UFPB, UFPE e UEB. Ao longo dos últimos anos, acolheu no seu grupo de investigação cerca de 30 colaboradores brasileiros em estágios de média duração e mais de 20 investigadores do seu leiros e 3 estrangeiros foram eleitos em assembleia-geral da ABC de 28 de Março último. A escolha de novos membros é feita com base na análise do respectivo processo de candidatura, obrigatoriamente iniciado e subscrito por um conjunto de membros efectivos da academia. Fundada a 3 de Maio de 1916, na cidade do Rio de Janeiro, com o nome Sociedade Brasileira de Sciencias (designação alterada em 1921 para a actual forma), a academia conta actualmente com cerca de 143 membros não brasileiros. 


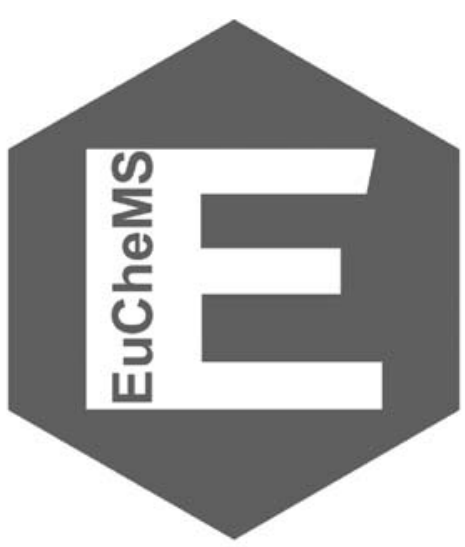

\section{A resposta da EuCheMS à proposta da Comissão Europeia relativa ao orçamento do Sétimo Programa Quadro}

A EuCheMS, acolhe com satisfação a proposta da Comissão Europeia (CE) relativa a investigação e tecnologia para o período 2007-2013 (Sétimo Programa Quadro, PQ7) que incluiu uma descrição detalhada do orçamento proposto de 67,8 mil milhões de euros.

O compromisso em simplificar a carga burocrática das candidaturas é bem vindo, sendo com satisfação que se verifica que o orçamento foi quase duplicado, para dar resposta à eventual so- brelotação de submissões. Contudo, é importante que definido o orçamento final, tal não sirva de motivo para os Estados Membros da EU reduzirem as suas contribuições nacionais.

A química é uma disciplina central em oito dos nove temas identificados pelo proposto Programa "COOPERATION" e contribui de forma significativa para fazer a ponte entre as actividades de investigação do Programa "IDEAS", cuja implementação constitui uma resposta efectiva à preocupação sobre o sub-financiamento da investigação fundamental na Europa.

Especialização e desenvolvimento de carreiras encontram-se cobertos pelo Programa "PEOPLE", enquanto o Programa "CAPACITIES" está focado no empreendedorismo através do suporte das PME's e da criação de relações duradouras entre a indústria e a universidade.

A EuCheMS reconhece a importância global da sustentabilidade para a indústria e para os consumidores, estando por isso empenhada no desenvolvimento de uma Plataforma Tecnológica Europeia (PTE) em Química Sustentável. A química e os químicos têm um papel crucial na segurança e qualidade ali- mentar e por isso a EuCheMS está também envolvida numa PTE Alimento para a Vida. O desenvolvimento de parcerias públicas/privadas nessas e noutras áreas estimulará a cooperação transnacional, e optimizará o impacto económico e social das actividades de investigação referenciadas.

A proposta da CE para O PQ7 ilustra a importância do Triângulo do Conhecimento, constituído por investigação e tecnologia, educação e inovação; esses sectores constituem os alicerces do programa do "EuCheMS First European Chemical Congress" que terá lugar em Budapeste de 27 a 31 de Agosto de 2006 (www.euchems-budapest2006.hu).

Este encontro juntará investigadores académicos e da indústria, professores, políticos, legisladores e consumidores, numa discussão e debate alargado sobre o papel da química na economia Europeia e ilustrará os potenciais benefícios para os consumidores europeus. Uma das particularidades do congresso consiste no participação activa de sete Laureados com o Prémio Nobel em contacto directo com estudantes e jovens investigadores (EuCheMS nota de imprensa).

JLF

\section{7. ${ }^{\circ}$ Encontro Nacional de Química-Física}

O 7. ${ }^{\circ}$ Encontro Nacional de Química-Física da Sociedade Portuguesa de Química teve lugar no Departamento de Química da Faculdade de Ciências da Universidade do Porto, entre 5 e 7 de Maio de 2005. Este Encontro contou com a participação de cerca de 130 colegas oriundos de 20 instituições nacionais e estrangeiras, tendo sido apresentadas 6 lições plenárias, 13 comunicações convidadas, 14 comunicações orais de curta duração e cerca de 70 comunicações em painel. Assim, a Comissão Organizadora congratula-se por se ter conseguido dar uma panorâmica geral da investigação científica que se está a desenvolver em Portugal nesta importante área da química, tanto a nível qualitativo como quantitativo. Da grande variedade de temas abordados destacam-se a termoquímica, a electroquímica, a espectroscopia, a fotoquímica, a química de superfícies e de polímeros, a tecnologia de novos materiais, e a química teórica e computacional. Queremos também realçar o clima agradável que se estabeleceu entre os participantes e que muito ajudou à troca de ideias e de resultados científicos. Esperamos, portanto, que este Encontro tenha servido para nos conhecermos melhor e estabelecer contactos.

Durante o Encontro realizou-se uma reunião da Divisão de Química-Física, com a eleição do próximo Presidente da Divisão como único ponto da ordem de trabalhos. Foi eleito por unanimidade dos presentes o nosso colega Rui Fausto Martins Ribeiro da Silva Lourenço, do Departamento de Química da Faculdade de Ciências e Tecnologia da Universidade de Coimbra para o biénio 2006-2007. Desejamos-Ihe o maior sucesso no desempenho das suas novas funções e em particular na organização do 8. Encontro Nacional de Química-Física em 2007.

Alexandre L. Magalhães

Presidente da Divisão de Química-Física

(2004-2005) 